\title{
Old age in health and disease
}

\section{Lessons from the oral cavity}

\author{
Jonathan A. Ship, DMD, and Bruce J. Baum, DMD, PhD, ${ }^{b}$ Ann Arbor, Mich., and \\ Bethesda, Md. \\ UNIVERSITY OF MICHIGAN SCHOOL OF DENTISTRY AND NATIONAL INSTITUTE OF DENTAL \\ RESEARCH, NATIONAL INSTITUTES OF HEALTH
}

\begin{abstract}
It is not clear if aging distinctions can be made at the level of an organ or organism. The purpose of this study was to determine if a general definition of systemic aging, primary aging (influence of the passage of time), versus secondary aging (influence of extrinsic factors), can be used to discriminate the functional status of an individual organ system, the oral cavity. Thirty healthy, nonmedicated subjects (that is, those who exhibit primary aging) and 42 persons being treated for medical problems and taking prescription medications (that is, those who exhibit secondary aging), aged 75 to 96 years, from the oral physiology component of the Baltimore Longitudinal Study of Aging were evaluated. A standardized examination assessed gingival, periodontal, dental, and oral mucosal tissues. There were few substantive differences in oral health and function between primary and secondary aging subjects. Thus use of broad definitions of aging in an organism did not lead to meaningfut predictions of the health or function of an individual organ system. Furthermore, the similarity in the oral condition between both groups studied here suggests substantial resiliency of the oral cavity during aging. (Oral Surg Oral Mfd Oral PATHOL 1993:76:40-4)
\end{abstract}

There is a continuing interest in understanding the influence of aging on physiologic processes. The goals of these efforts are to define which processes change and which ones remain stable as a consequence of the passage of time. This knowledge ideally will permit more precise recognition of disease and thus early intervention.

Earlier studies of aging frequently compared medically compromised older persons with healthier younger ones and inappropriately concluded that physiologic function in many organ systems was altered as the result of aging. Unfortunately, these conclusions fostered a belief that aging was associated with generalized deterioration. In the last two decades, gerontologic research has addressed this problem, and multiple definitions of aging have evolved. ${ }^{1-3}$

In 1969 Busse described aging by distinguishing two pathways by which overall functional status in an elder may occur. Primary aging was defined as the influence of the passage of time on a person, independent of extrinsic influences or disabilities including stress, trauma, or disease. The intent of this definition

\footnotetext{
${ }^{a}$ Formerly Senior Investigator, Clinical Investigations and Patient Care Branch, National Institute of Dental Research, National Institutes of Health; Currently, Associate Professor and Director of Hospital Dentistry; University of Michigan School of Dentistry. ${ }^{b}$ Clinical Director, National Institute of Dental Research, and Chief, Clinical Investigations and Patient Care Branch, National Institute of Dental Research, National Institutes of Health. Copyright $\odot 1993$ by Mosby-Year Book, Inc. $0030-4220 / 93 / \$ 1.00+.10 \quad 7 / 13 / 46625$
}

was to delineate a "pure aging" phenomena. The other pathway, secondary aging, was defined as growing old in the presence of external influences. ${ }^{1}$ These definitions arose out of the need to distinguish between the effects of aging on general physiologic function and those of diseases and other circumstances that affect older persons but do not necessarily reflect the aging phenomena.

Although definitions of aging such as primary and secondary aging have been conceptually useful, it is not clear if such distinctions should actually be made at the level of an organ or organism. There is an emerging view that it is difficult to use simplitied definitions of aging. ${ }^{4}$ If a person is systemically healthy, can it be expected that every organ system has undergone primary aging? Conversely, if an elder is being treated for several unrelated systemic conditions, have all other organ functions manifested secondary aging effects? The present study attempts to apply Busse's concepts of primary and secondary aging to one organ system, the oral cavity. Specifically, we asked if the oral cavity of an older person with medical problems in other systems is less healthy than that of an age peer without such conditions? The oral cavity is a particularly useful system with which to address this question. It is responsible for two essential functions, the production of speech and the initiation of alimentation and, importantly, it is readily accessible to direct examination. It also frequently manifests secondary effects of numerous systemic diseases and treatments. 


\section{METHODS}

\section{Subjects}

The study population consisted of 72 subjects ( 27 men and 45 women) between the ages of 75 and 96 years, who were volunteer participants in the oral physiology component ${ }^{5}$ of the Baltimore Longitudinal Study of Aging. ${ }^{6}$ This small cohort of 72 persons represents the entire complement of persons who met the aforementioned definitions of primary and secondary aging. All subjects studied were community-dwelling, ambulatory, white, of middle socioeconomic class, and received regular dental care (at least one visit per year). Participants were examined by a physician and disease diagnoses were based upon clinical and laboratory results. ${ }^{4}$ Subjects were divided into two groups according to medical health status. Persons who were neither being treated for any systemic disease nor taking prescription medications were termed primary aging subjects; those being treated for any systemic disease(s) and taking prescription medications were termed secondary aging subjects. The most frequent medical problems among secondary aging subjects were cerebrovascular diseases, coronary artery disease, diabetes, hypertension, hypothyroidism, and prostate cancer. The most frequent prescription medications used were angiotensin-converting enzyme inhibitors, $\beta$ adrenoreceptor blockers, calcium channel blockers, cardiac glycosides, diuretics, oral hypoglycemics, platelet inhibitors, and thyroid hormone replacements. All study participants underwent a standardized oral examination and interview ${ }^{5,7,8}$ performed by one of us (J.A.S.). Specifically, gingival, periodontal, dental, and oral mucosal tissues were examined. In aggregate, these measures provide a general picture of oral health.

\section{Dental, periodontal, and oral mucosal measurements}

Dental and periodontal parameters used criteria established by the National Institute of Dental Research National Survey of Oral Health of U.S. Adults. ${ }^{9}$ The following dental measurements were recorded for each participant: tolal number of teeth (excluding third molars), decayed-missing DMFT DMFS teeth score, decayed-missing-filled-surfaces score, number of teeth and dental surfaces with coronal and cervical caries, and number of teeth and dental surfaces with coronal and cervical restorations. The following gingival and periodontal parameters were assessed on the mesiobuccal and midbuccal surfaces of all teeth: dental plaque, gingival bleeding, supra- and sub-gingival calculus, amount of periodontal recession, pocket depth, and periodontal attach-
Table I. Study population*

\begin{tabular}{l|c|c}
\hline & $\begin{array}{c}\text { Primary } \\
\text { aging } \\
\text { subjects }\end{array}$ & $\begin{array}{c}\text { Secondary } \\
\text { aging } \\
\text { subjects }\end{array}$ \\
\hline $\begin{array}{c}\text { Sample size } \\
\text { Age (years) }\end{array}$ & $\begin{array}{c}30 \\
\text { Number of medical } \\
\text { conditions }\end{array}$ \\
$\begin{array}{l}\text { Number of prescription } \\
\text { medications }\end{array}$ & 0 & 42 \\
$\begin{array}{l}\text { * Results expressed as mean } \pm \text { sd. } \\
\text { †Range. }\end{array}$ & $2.1 \pm 1.0(1-6) \dagger$ \\
\end{tabular}

ment level. All measurements were taken with an National Institute of Dental Research color-coded periodontal probe, and where applicable, were rounded down to the nearest millimeter. ${ }^{9}$ The extent and severity of periodontal attachment level was assessed ${ }^{10}$ because increased attachment level is considered to be a diagnostic determinant of periodontal disease. ${ }^{11}$ Extent is the prevalence of sites in a mouth with an attachment level of $2 \mathrm{~mm}$ or greater, whereas severity is the average amount of the attachment level in these sites. ${ }^{10}$ The status of the oral mucosa was assessed with the use of the National Health and $\mathrm{Nu}$ trition Examination Surveys III rating scale primarily on the basis of clinical diagnoses. ${ }^{12}$

\section{Statistical analyses}

The data were analyzed for differences between primary and secondary aging subjects. A Student's $t$ test was used where mean values had a normal distribution, and a Mann-Whitney procedure was used for nonparametric values. Chi-square and two-way Fisher exact tests were performed for prevalence data. Data were analyzed with the use of the RS1 software package (BBN Software Products Corp., Cambridge Mass.). A criterion of $p<0.05$ was accepted as statistically significant unless otherwise indicated.

\section{RESULTS}

A summary of the population studied is displayed in Table I. No gender differences were observed for any of the clinical parameters examined, and subsequent analyses wcre therefore performed with men and women combined. The two study groups were similar in age but markedly different with respect to health status (Table I).

The results of dental measurements expressed in terms of tooth surfaces are shown in Table II. Results based on numbers of teeth gave comparable results (data not shown). In general, there were few differences between subject groups. Importantly, both 
Table II. Dental parameters*

\begin{tabular}{l|c|c|c}
\hline \multicolumn{1}{c|}{ Dental Parameter } & $\begin{array}{c}\text { Primary } \\
\text { aging subjects } \\
(n=30)\end{array}$ & $\begin{array}{c}\text { Secondary } \\
\text { aging subjects } \\
(n=42)\end{array}$ & Difference \\
\hline Number of teeth & $21.3 \pm 1.2$ & $19.7 \pm 1.3$ & NS \\
Number of surfaces with coronal caries & $2.2 \pm 1.1$ & $0.6 \pm 0.2$ & NS \\
Number of surfaces with cervical caries & $0.4 \pm 0.2$ & $1.0 \pm 0.3$ & NS \\
Number of surfaces with coronal restorations & $40.1 \pm 4.3$ & $46.1 \pm 4.3$ & NS \\
Number of surfaces with cervical restorations & $2.4 \pm 0.5$ & $4.6 \pm 0.6$ & $\mathrm{p}=0.01 \dagger$ \\
Number of missing surfaces & $28.2 \pm 4.9$ & $36.8 \pm 5.6$ & $\mathrm{NS}$ \\
DMFS & $76.1 \pm 5.3$ & $91.1 \pm 4.0$ & $\mathrm{p}=0.02 \dagger$ \\
\hline
\end{tabular}

NS = not significant

*Results expressed as mean \pm sem.

iStudent's t-test.

Table III. Gingival and periodontal parameters*

\begin{tabular}{|c|c|c|c|}
\hline Parameter & $\begin{array}{c}\text { Primary } \\
\text { aging subjects } \\
(n=30)\end{array}$ & $\begin{array}{c}\text { Secondary } \\
\text { aging subjects } \\
(n=42)\end{array}$ & Difference \\
\hline \multicolumn{4}{|l|}{ Gingival parameters $\dagger$} \\
\hline Dental plaque & $48 \pm 4 \%$ & $55 \pm 4 \%$ & NS \\
\hline Gingival bleeding & $20 \pm 3 \%$ & $25 \pm 3 \%$ & NS \\
\hline Calculus & $22 \pm 4 \%$ & $25 \pm 4 \%$ & NS \\
\hline \multicolumn{4}{|c|}{ Periodontal parameters } \\
\hline Recession & $1.1 \pm 0.1 \mathrm{~mm}$ & $1.1 \pm 0.1 \mathrm{~mm}$ & NS \\
\hline Pocket depth & $1.7 \pm 0.1 \mathrm{~mm}$ & $1.8 \pm 0.1 \mathrm{~mm}$ & NS \\
\hline Attachment level & $2.6 \pm 0.2 \mathrm{~mm}$ & $2.6 \pm 0.2 \mathrm{~mm}$ & NS \\
\hline \multicolumn{4}{|c|}{ Extent and severity of attachment level } \\
\hline Extent & $71 \pm 4 \%$ & $71 \pm 4 \%$ & NS \\
\hline Severity & $3.3 \pm 0.1 \mathrm{~mm}$ & $3.3 \pm 0.1 \mathrm{~mm}$ & NS \\
\hline
\end{tabular}

NS = not significant.

*Results expressed as mean \pm sem.

$\doteqdot$ Percentage of dental sites.

groups retained comparable numbers of teeth and had similar caries activity. Subjects in the secondary aging group demonstrated statistically more restored cervical tooth surfaces, which contributed in part to their higher DMFS score.

The percentage of tooth surfaces with dental plaque, gingival bleeding, and calculus were not statistically different between the study groups (Table III). Furthermore, no statistically significant differences were observed for average amounts of gingival recession, pcriodontal pocket depth, or attachment level between the two groups. In both groups, the extent of attachment level of $2 \mathrm{~mm}$ or greater was $71 \%$, and the severity was $3.3 \mathrm{~mm}$.

Similarly, mucosal examination revealed no statistically significant differences between the groups. A summary of clinical diagnoses according to the $\mathrm{Na}-$ tional Health and Nutrition Examination III criteria is given in Table IV. Slightly more primary aging subjects $(47 \%)$ had no clinical diagnoses compared with secondary aging subjects $(36 \%)$, but this effect was not statistically significant.

\section{DISCUSSION}

Persons who experienced either primary or secondary aging with few exceptions had remarkably similar oral conditions. Indeed, both groups exhibited better oral health compared with that reported for older persons in several large, general population studies. ${ }^{9}, 13,14$ The findings in the present study have at least two significant implications. The first is that there is little substantive difference in the overall health and function of the particular organ system examined-the oral cavity - when described in terms of the primary and secondary aging of the human organism. The second is that the use of such broad definitions of aging in an organism ${ }^{1}$ does not necessarily lead to meaningful predictions of the health and function of an individual organ system.

The first implication is surprising because numer- 
ous systemic conditions ${ }^{15}$ and medications ${ }^{16}$ are known to have deleterious consequences to oral health in the elderly. There was one directly measured significant change observed in this study between primary and secondary aging subjects; however, it was modest. Secondary aging subjects had a greater number of cervical dental restorations. The presence of cervical restorations implies a previous history of cervical caries, which are typically more common in the elderly and associated with salivary gland hypofunction. This difference, observed in people with otherwise very similar oral health, suggests that even more medically compromised older persons may be especially susceptible to this type of caries.

In aggregate, the vast majority of oral health parameters measured here were statistically indistinguishable between both primary and secondary aging subjects, which indicates a substantial resiliency of the oral tissues. Further, in the context of results from other studies, ${ }^{17}$ it seems reasonable to conclude that the oral condition in generally healthy elderly persons is cornparable to that seen in generally healthy young adults. This constancy of function seems desirable for an organ system forced to perform while exposed to numerous external insults.

A caveat to this reasoning is that whereas persons were examined who fully met Busse's aforementioned definition of secondary aging, these persons had quite well-controlled systemic diseases. The secondary aging group consisted of community-dwelling, ambulatory, noncognitively impaired persons, who on average had only two diseases and wcre taking two prescription medications. This population is not typical of all elderly people but was used to provide a clear experimental test for the question posed in the study. We suspect, however, that persons who exhibit an extreme of secondary aging (that is, the presence of multiple adverse exogenous influences) will have a deterioration in oral health. ${ }^{15}$

Another caveat to the study is that the investigation was cross-sectional by design. Therefore although the results seem clear, the conclusions should be reexamined in the context of a longitudinal study. ${ }^{18}$

The second implication of this study is that precise definitions of aging are needed at an organ system level, reflecting an interaction of disease and aging on physiology that is probably organ specific. General definitions such as primary and secondary aging when applied at the level of an organism are likely to be imprecise and impractical. This should not be surprising because there is considerable evidence that organ systems do not age at the same rate across the human life span. Aging, although a universal phenomenon, is not a uniform process across physiologic systems. ${ }^{19}$
Table IV. Oral mucosal parameters*

\begin{tabular}{l|c|c}
\hline $\begin{array}{c}\text { National Health } \\
\text { and Nutrition }\end{array}$ & $\begin{array}{c}\text { Primary } \\
\text { aging } \\
\text { subjects } \\
(n=30)\end{array}$ & $\begin{array}{c}\text { Secondary } \\
\text { aging } \\
\text { subjects } \\
(n=42)\end{array}$ \\
\hline None & 14 & 15 \\
Actinic keratosis & 1 & 2 \\
Amalgam tattoo & 3 & 3 \\
Angular cheilitis & 1 & 0 \\
Pseudomembranous candidiasis & 0 & 1 \\
Cheek or lip biting & 2 & 8 \\
Denture stomatitis & 4 & 9 \\
Erythroplakia & 1 & 3 \\
Homogeneous leukoplakia & 2 & 4 \\
Nicotinic stomatitis & 1 & 0 \\
Fissured tongue & 2 & 2 \\
Geographic tongue & 1 & 1 \\
Nonspecific tumor & 3 & 3 \\
Nonspecific ulcer & 2 & 2 \\
Cleft lip/palate & 1 & 0 \\
\hline
\end{tabular}

*Multiple diagnoses could be given to each subject.

For example, glomerular filtration rates and creatinine clearance begin to decline around age 30 in healthy persons and progressively decrease thereafter. ${ }^{20,21}$ Glucose tolerance declines after age 60 in healthy subjects, ${ }^{22}$ whercas salivary gland function remains age-independent in subjects not being treated for medical problems. ${ }^{23-25}$

Thus to understand the influence of aging and disease on human physiology, it appears necessary to define the distinction between health and disease at the level of each organ system. For the system that was examined in this study, the results demonstrate that acceptable oral health in an aging person can clearly exist in the presence of certain well-controlled systemic diseases. The process of distinguishing organ-specific health versus disease appears not amenable to simple generalization but rather requires detailed information from substantial investigative effort. Given the increased proportion of elderly persons in our society, organ-specific definitions of discase would seem to be a prerequisite necessary for accurate health-care planning for the future.

We thank Dr. James Fozard of the National Institute of Aging for invaluable assistance throughout the course of this study and Dr. James Lipton and Dr. Ingrid Valdez of the National Institute of Dental Research for helpful comments on previous editions of the manuscript.

\section{REFERENCES}

1. Busse EW. Theories of aging. In: Busse EW, Pfeiffer E, eds. Behavior and adaptation in later life. Boston: Little Brown, 1969:11-32.

2. Rowe JW, Kahn RL. Human aging: usual and successful. Science 1987;237:143-9. 
3. Baum BJ, Ship JA, Wu AJ. Salivary gland function and aging: a model for studying the interaction of aging and systemic disease. Crit Rev Oral Biol Med 1992;4:53-64.

4. Metter EJ, Walega D, Metter EL, et al. How comparable are healthy 60 - and 80-year-old men? I Gerontol 1992;47:M73-8

5. Baum B3. Characteristics of the oral physiology component of the Baltimore longitudinal study of aging. Community Dent Oral Epidemiol 1981;9:128-34.

6. Shock NW, Greulich RC, Andres R, et al. Normal human aging: the Baltimore longitudinal study of aging. NIH Publication No. 84-2450. Washington, DC: U.S. Government Printing Office, 1984.

7. Fox PC, Van der Ven PF, Sonies BC, Weiffenbach JM, Baum BJ. Xerostomia: evaluation of a symptom with increasing significance. J Am Dent Assoc 1985;1 10:519-25.

8. Ship JA, Fox PC, Baum BJ. How much saliva is enough? normal function detined. J Am Dent Assoc 1991;122:63-9.

9. Miller AJ, Brunelle JA, Carlos JP, Brown LJ, Loe H. Oral health of United States adults. U.S. Department of Health and Human Services. NIH Publication No. 87-2868. National Institutes of Health, Public Health Service, Washington, DC: Government Printing Office 1987.

10. Carlos JP, Wolfe MD, Kingman A. The extent and severity index: a simple method for use in epidemiologic studies of periodontal disease. J Clin Periodontol 1986:13:500-5.

11. Clerehugh V, Lennon MA. The attachment level as a measure of early periodontitis. Community Dent Health 1984;1:33-40.

12. National Health and Nutrition Examination Survey III Oral Health Survey Methods. Rockville, Maryland: Westat Inc, 1984.

13. Beck JD, Koch GG, Rozier RG, Tudor GE. Prevalence and risk indicators for periodontal attachment loss in a population of older community-dwelling blacks and whites. J Periodontal 1990;61:521-8.

14. Hand JS, Hunt RJ, Kohout FJ. Five-year incidence of tooth loss in Iowans age 65 or older. Community Dent Oral Epidemiol 1991;19:48-51.

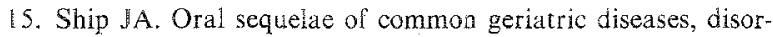
ders, and impairments. Clin Geriatr Med 1992;8:483-97.

16. Sreebny LM, Schwartz SS. A reference guide to drugs and dry mouth. Gerodontology 1986;5:75-99.

17. Baum B.I, Ship JA. The oral cavity. In: Hazzard WR, Andres $R$, Bierman EL, Blass JP, eds. Principles of geriatric medicine and gerontology, 2nd ed. New York: McGraw-Hill, 1990:41321.

18. Elahi VK, Elahi D, Andres R, Tobin JD, Butler MG, Norris AH. A longitudinal study of nutritional intake in men. J Gerontol 1983;38:162-80.

19. Fozard JL, Metter EJ, Brant LJ. Next steps in describing aging and disease in longitudinal studies. J Gerontol 1990;45: P116-P27.

20. Lindeman RD, Tobin J, Shock NW. Longitudinal studies on the rate of decline in renal function with age. $J$ Am Geriatr Soc $1985 ; 33: 278-85$.

21. Rowe JW, Andres R, Tobin JD, Norris AH, Shock NW. The effect of age on creatinine clearance in man: a cross-sectional and longitudinal study. J Gerontol 1976;31:155-63.

22. Shimokata H, Muller DC, Fleg JL, Sorkin J, Ziemba AW, Andres R. Age as independent determinant of glucose tolerance. Diabetes 1991;40:44-51.

23. Baum BJ. Evaluation of stimulated parotid saliva flow rate in different age groups. J Dent Res 1981;60:1292-6.

24. Tylenda CA, Ship JA, Fox PC, Baum BJ. Evaluation of submandibular salivary flow rate in different age groups. J Dent Res 1988;67:1225-8.

25. Ship JA, Baum BJ. Is reduced salivary flow normal in old people? Lancet 1990;336:1507.

Reprint requests:

Jonathan A. Ship, DMD

University of Michigan School of Dentistry

Department of Oral Medicine, Pathology, and Surgery

1011 N. University

Ann Arbor, MI 48109-1078 